Case report

\title{
Cardiac Hydatid Cyst: A Case Report
}

\author{
Edlira Rruci ${ }^{1,2}$, Ketjon Menkshi ${ }^{1}$, Saimir Kuçi ${ }^{10}$, Afërdita Veseli ${ }^{1}$, Gentian Vyshka ${ }^{2, *}$ \\ ${ }^{1}$ Service of Cardiological Surgery, University Hospital Center of Tirana, Albania \\ ${ }^{2}$ Biomedical and Experimental Department, Faculty of Medicine, University of Medicine in Tirana, Albania \\ *Correspondence: gvyshka@gmail.com
}

\begin{abstract}
Although rarely, echinococcosis might present cardiac involvement, with cysts growing inside myocardial structures of arising adjacent to heart. A careful differential diagnosis with other mass formations and rare cardiac tumours is necessary, whenever there is a clinical and radiological suspicion. Imaging studies and serology will establish diagnosis. A multidisciplinary approach is warranted in all cases, with surgical intervention being unavoidable in most settings. Patients generally present with chest pain and dyspnoea. Cases need a close follow up of their postoperative course, while being treated appropriately with albendazole (or mebendazole) for prevention of recurrences.
\end{abstract}

Keywords: Hydatid disease; Cardiac involvement; Echo-lucent structures; Chest pain

How to cite this paper: Rruci, E., Menkshi, K., Kuçi, S., Veseli, A., \& Vyshka, G. (2022). Cardiac Hydatid Cyst: A Case Report. Global Journal of Medical Case Reports, 2(1), 1-4. Retrieved from https://www.scipublications.com/journal/index.php/gjmcr/article/view/195

Received: December 01, 2021

Accepted: January 09, 2022

Published: January 10, 2022

Copyright:@ 2021 by the authors. Submitted for possible open access publication under the terms and conditions of the Creative Commons Attribution (CC BY) license (http://creativecommons.org/licenses /by/4.0/).

\section{Introduction}

Cardiac hydatidosis is a rare manifestation of Echinococcus infection. It represents 0.5 to $2 \%$ of hydatic disease [1]. The most common localization is the myocardium of the left ventricle but can also touch the right ventricle, atrium, pericardium, interventricular septum, and pulmonary artery. Clinical presentation varies, ranging from clinical latency or minor symptoms to cardiogenic shock and sudden death. This case describes an intramyocardial hydatid cyst of the left ventricle. Cardiac imaging and hydatid serology can establish diagnosis. Therapy management should combine both surgery and medical treatment by albendazole or mebendazole.

\section{Case Presentation}

A 14-year-old male living in a rural area in north Albania, presented to the Emergency Department as a cardiogenic shock: $\mathrm{BP} 60 / 40 \mathrm{~mm} \mathrm{Hg}$, temperature $37.8^{*} \mathrm{C}$ and paroxysmal supraventricular tachycardia. The patient refers of two-week history of cough, chest pain, palpitations, dyspnoea, fatigue, headache, nausea, abdominal pain. He was transferred immediately to the Cardiac Intensive Care Unit. At this time, his pulse was regular but very week, with a heart rate of $108 \mathrm{bpm}$ and his blood pressure was $90 / 60 \mathrm{~mm}$ Hg. Hematologic and biochemical laboratory exams were normal. Chest $x$ ray showed a localized bulge at the apex of the heart. 


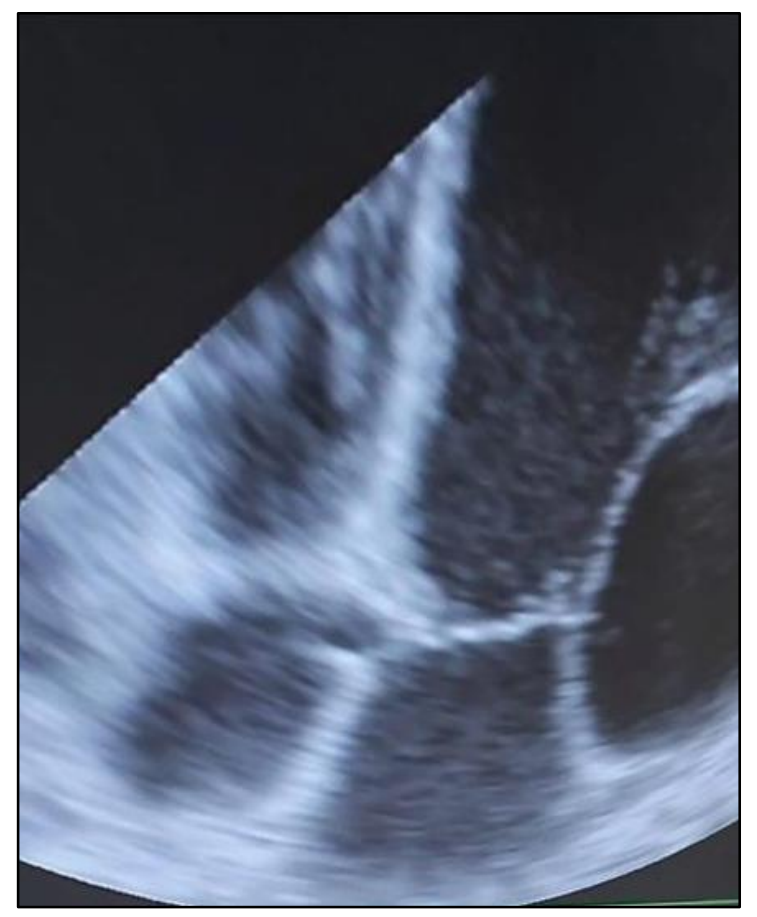

Figure 1. Echo-lucent cyst shown in the cardiac echocardiography.

Transthoracic echocardiography (TTE) demonstrated an echo-lucent cyst measuring $7 \times 7 \mathrm{~cm}$ on the left ventricular free wall and severe mitral regurgitation secondary to compressive effect of huge mass, no pericardial effusions. Mitral leaflets were normal.

Cardiac magnetic resonance (MRI) revealed a large lesion at the myocardium of the left ventricular free wall. Thoracic Computed tomography of the lungs identified no additional organ involvement and abdominal ultrasounds were negative.

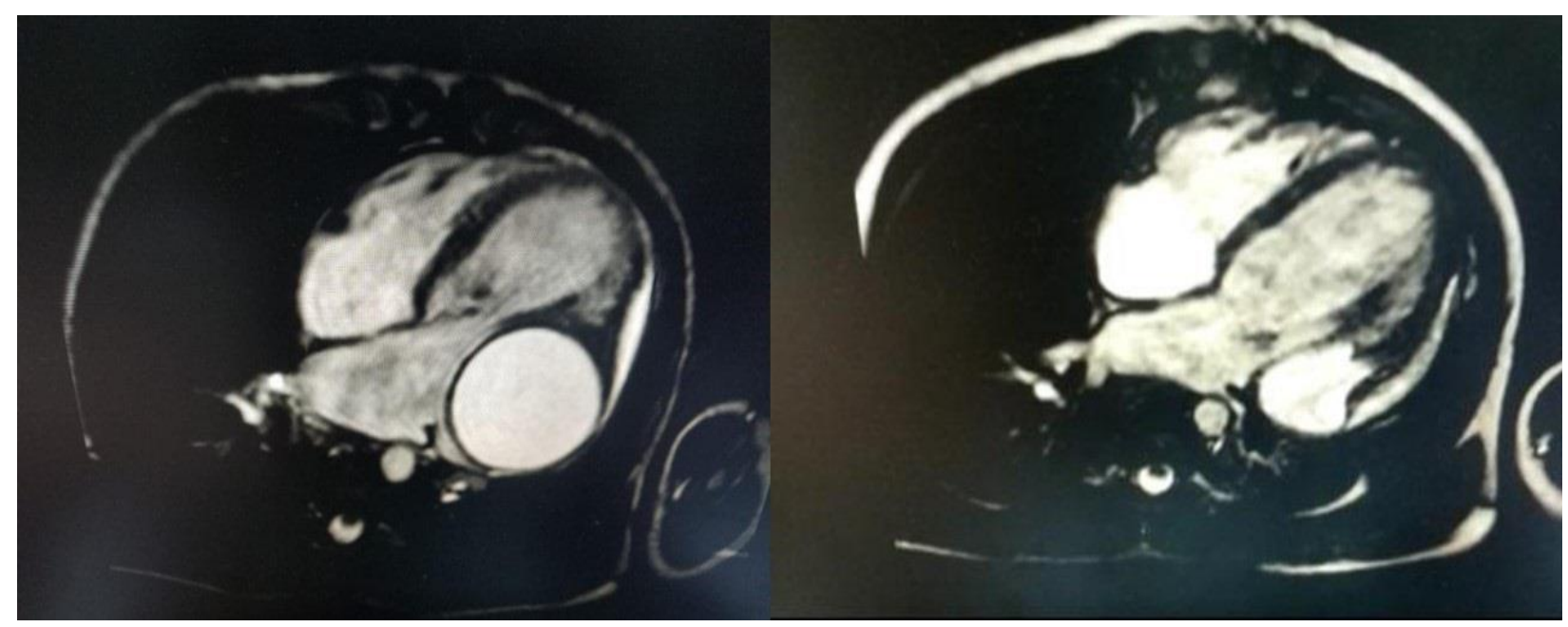

Figure 2. Magnetic resonance imaging of thoracic structures showed the presence of cyst.

Diagnosis of cardiac echinococcosis was made and the patient was referred for cardiac operation. Surgery was realized through a median sternotomy. We first used aspiration with a needle connected directly to the aspirator. Cardiopulmonary bypass was used due to the least risk of spillage of cyst contents during the procedure and sponges soaked with hypertonic saline solution were distributed throughout the pericardial cavity to prevent local invasion by the parasite. 
Once systemic contamination was prevented, the cyst was widely opened and thoroughly excised under cardiopulmonary bypass. Histologic examination confirmed the diagnosis of HC and ELISA test was positive for echinococcosis. The patient started medical treatment with albendazole ( $400 \mathrm{mg}$ twice daily) for 12 weeks and was discharged on seventh postoperative day symptom free.

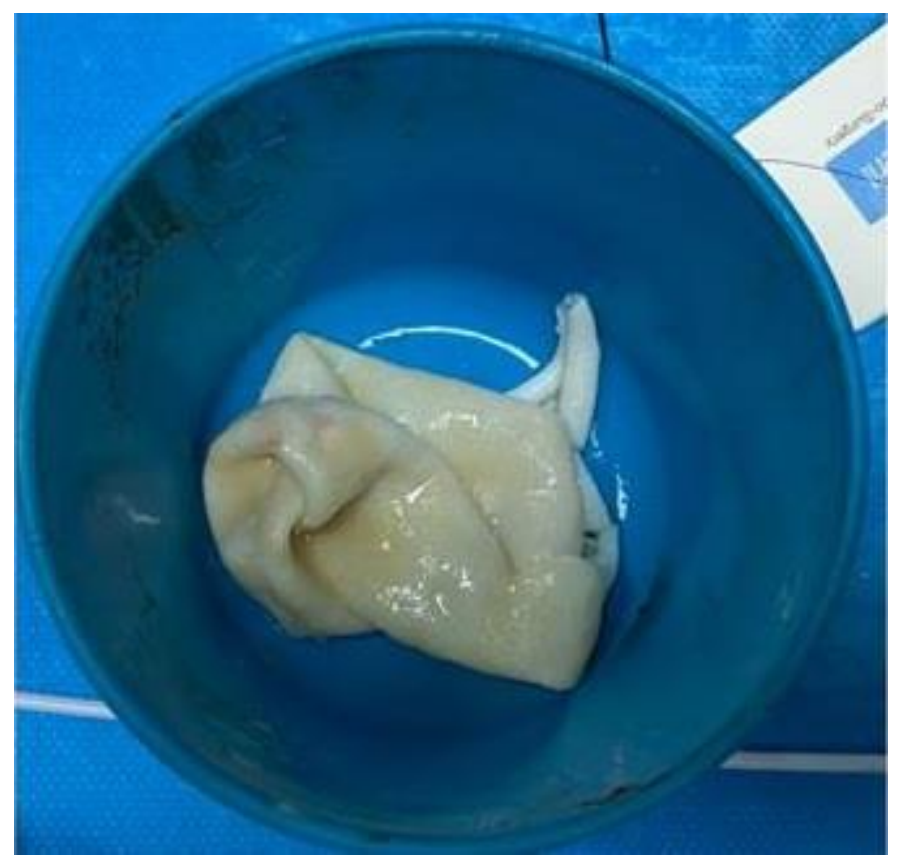

Figure 3. Postoperative view of the excised hydatid cyst.

\section{Discussion}

Hydatid disease is a larval cestodosis. It is caused by a cestode of the Echinococcus family that mainly parasites dogs and other canids. It is usually located in the liver or lungs.

Cardiac hydatid cyst involvement is very uncommon and represents 0.5 to $2 \%$ of hydatic disease [1]. It is located at the left ventricle (60\% of cases), right ventricle (10\%), pericardium $(7 \%)$, pulmonary artery $(6 \%)$, left atrium $(6 \%)$, and interventricular septum $(4 \%)$ [2].

It is usually secondary to an extension of larvae through the systemic or pulmonary circulation or as a direct extension from near organs [3]. In our case, hydatid cyst disease was isolated to the left ventricle.

Our case report was about a 14-year-old patient as the majority of patients in the literature [4]. He presented with signs of heart failure. In the other studies, the circumstances of discovery were varied depending on the size, location, number of the cyst, and the presence of complications, ranging from clinical latency to fever, chest pain, dyspnoea, weakness, and at worst anaphylactic shock due to cyst rupture into the bloodstream or sudden death [1]. Other complications occur, such as systemic or pulmonary hydatid embolism, valve obstruction, and mitral regurgitation secondary to papillary muscle involvement, atrioventricular conduction defects, and arrhythmias [1].

Different methods can help for the diagnosis of cardiac hydatidosis, such as a prior history of hydatid disease, the presence of eosinophilia and abnormal shape of the heart shadow, or sometimes a calcified spherical mass at the chest X-ray [5]. Echocardiography, $\mathrm{CT}$, and magnetic resonance imaging (MRI) findings can confirm the diagnosis. Echocardiography is the method of choice that shows the typical image of a mono- or multi-vesicular cyst, with a honeycomb appearance. The echo-lucent and multi-septate nature of 
hydatid cysts are characteristic of the Echinococcus cyst, but sometimes, it may be absent and should be considered in the differential diagnosis of cardiac tumoral lesions [5, 6]. The hydatid serology was positive in our patient and often positive in the literature, but its negativity does not eliminate the diagnosis $[7,8]$.

Surgery is of paramount importance because of the risk of hydatid cyst rupture. It consists of the excision of cysts and pericardial drainage if present [9]. In addition, medical treatment with albendazole or mebendazole is recommended to reduce the risk of recurrence $[10,11]$.

Postoperative, serological assessment is justified every 2 months for 2 years to detect a possible recurrence [12].

\section{Conclusion}

Cardiac Hydatid cyst is a very rare disease. Chest pain is the most common symptom. Surgery is the main modality of treatment.

\section{References}

[1] Kosecik M, Karaoglanoglu M, Yamak B. Pericardial hydatid cyst presenting with cardiac tamponade. Can J Cardiol. 2006 Feb;22(2):145-7.

[2] Dursun M, Terzibasioglu E, Yilmaz R, Cekrezi B, Olgar S, Nisli K, Tunaci A. Cardiac hydatid disease: CT and MRI findings. AJR Am J Roentgenol. 2008 Jan;190(1):226-32.

[3] Sirlak M. Cardiac Hydatid Cysts-Review of Recent Literature. Journal of Veterinary Medicine and Research. 2017; 4(8):1102.

[4] Bakkali A, Jaabari I, Bouhdadi H, Razine R, Bennani Mechita N, El Harrag J, Belkhadir A, Benlafqih C, Laaroussi M. Les kystes hydatiques cardiaques à propos de 17 cas opérés [Cardiac hydatid cyst about 17 operated cases]. Ann Cardiol Angeiol (Paris). 2018 Apr;67(2):67-73.

[5] Fazlinezhad A, Moohebati M, Azari A, Bigdeloo L. Acute pericardial tamponade due to ruptured multiloculated myocardial hydatid cyst. Eur J Echocardiogr. 2009 May;10(3):459-61.

[6] Moujahid M, Lamrani M, Tajdine MT, Daali M. Kyste hydatique du cœur. Sang Thrombose Vaisseaux. 2007 Nov 1;19(9):498-9.

[7] Miralles A, Bracamonte L, Pavie A, Bors V, Rabago G, Gandjbakhch I, Cabrol C. Cardiac echinococcosis. Surgical treatment and results. J Thorac Cardiovasc Surg. 1994 Jan;107(1):184-90.

[8] Giorgadze, Nadareishivili A, Goziridze M, Zodelava E, Nachkepia M, Grigolia G, Chekanov V. Unusual recurrence of hydatid cysts of the heart: report of two cases and review of the clinical and surgical aspects of the disease. J Card Surg. 2000 MayJun;15(3):223-8.

[9] Zhang X, Wei X, Ran L, Tang H. A rare case of cardiac alveolar echinococcosis. Eur Heart J. 2020 Jul 21;41(28):2698.

[10] Kurdal AT, Kahraman N, Iskesen I, Sirin BH. Unusual location of hydatid cyst: the posterior leaflet of tricuspid valve. Ann Ital Chir. 2010 May-Jun;81(3):211-4.

[11] Pilaca A, Vyshka G, Pepa A, Shytaj K, Shtjefni V, Boçari A, Beqiri A, Kraja D. A Neglected Zoonosis in Albania: why Echinococcosis is becoming a Surgeon's Exclusivity? Mediterr J Hematol Infect Dis. 2014 Feb 16;6(1):e2014013.

[12] Sabzi F, Madani H, Dabiri S, Pormotabed A, Faraji R. Thrombotic cardiac apex hydatid cyst. Indian Heart J. 2015 NovDec;67(6):577-80. 